\title{
REFLETINDO SOBRE O CUIDAR E O ENSINAR NA ENFERMAGEM
}

\author{
Alessandra Conceição Leite Funchal Camacho* \\ Fátima Helena do Espírito Santo**
}

\begin{abstract}
CAMACHO, A.C.L.F.; SANTO, F.H.do E. Refletindo sobre o cuidar e o ensinar na enfermagem. Rev.latinoam.enfermagem, Ribeirão Preto, v. 9, n. 1, p. 13-17, janeiro 2001.
\end{abstract}

Trata-se de uma reflexão sobre o cuidar e o ensinar em Enfermagem com base em experiências acadêmicas e profissionais nas áreas de pesquisa, ensino e extensão. Tem como objetivo contribuir para as discussões sobre a importância do estudante de enfermagem no processo de cuidar e ensinar e, sua participação efetiva em trabalhos cientificos, os quais podem possibilitar o desenvolvimento de uma consciência mais crítica sobre a realidade do ensino e da prática de Enfermagem.

UNITERMOS: enfermagem, reflexão, ensino, cuidado

\section{INTRODUÇÃO}

\section{Durante o Curso de Graduação em Enfermagem}

tive a oportunidade de atuar nas áreas de pesquisa, ensino e extensão e, tais experiências me impulsionaram tanto na busca de novos conhecimentos quanto, mais tarde, contribuíram para gratificantes conquistas e inúmeras descobertas no início de minha trajetória profissional.

Percorrendo novos caminhos, constatei que cuidar e ensinar são atividades essenciais no nosso cotidiano, e por isso mesmo, precisam ser cada vez mais interrelacionadas para o avanço da Enfermagem na qual estão inseridos e socializadas diversas formas de conhecimento.

Hoje, atuando no ensino de Graduação e na Assistência de Enfermagem, percebo que minhas experiências se articulam com a prática profissional despertando reflexões sobre o cuidar e o ensinar e suas dimensões na formação do estudante de enfermagem.

E porque é tão importante refletirmos sobre as dimensões do cuidar e ensinar? Porque, como muito bem diz PESSOA (1996), o estudante durante o Curso de Graduação ...além de lidar com o novo, tem que vivenciar um encontro.

$\mathrm{O}$ encontro que o autor se refere diz respeito a interação que se estabelece com o cliente, no qual o estudante precisa aprender a lidar com seus valores, suas emoções, medo e angústias ao cuidar do outro, que, por sua vez, também expressa seus sentimentos e valores ao interagir com o estudante.

O Ensinar nesses momentos mostra que ...cuidar significa presença, corpo - mente do aluno/professor junto do cliente - família. Ao vivenciar a relação com o cliente, o aluno estuda e desenvolve sua prática de aprendizado sobre o cuidado humano apreendendo a criar seu futuro fazer profissional, e, nesse processo de criação, ele concebe, organiza e expressa ações de cuidado (NUNES, 1998).

Entretanto, como ressalta WALDOW (1998), não existem receitas ou manuais de como ensinar cuidado. Na perspectiva do cuidado, professoras, ao realizarem o cuidado humano no cotidiano, intuirão e serão compelidas a, automaticamente desenvolverem novas estratégias e, experiências de aprendizagem mais dinâmicas e criativas.

Dentre estas estratégias destaca-se a manutenção do diálogo que favoreça a troca de experiências e a compreensão dos seus significados para cada estudante. Nesse sentido, PEREIRA (1995), chama a atenção para o currículo que passa a ser mais do que um conjunto de objetivos. Ele passa a constituir-se em um diálogo quanto à experiência vivida por professoras, estudantes, enfermeiras e clientes, ou seja, o ...ensinar transformase em aprender, no esforço de entender e o aprender em

* Enfermeira. Professora Substituta da Faculdade de Enfermagem da Universidade do Estado do Rio de Janeiro. Mestranda em Enfermagem pela Escola de Enfermagem Anna Nery da Universidade Federal do Rio de Janeiro. Endereço: Rua: Torres Homem, 1114 - Ap. 801 - Vila Isabel - 20551-070 - Rio de Janeiro - Rio de Janeiro - Brasil

** Enfermeira. Professor Assistente da Escola de Enfermagem Aurora de Afonso Costa da Universidade Federal Fluminense. Mestre e Doutoranda em Enfermagem pela Escola de Enfermagem Anna Nery da Universidade Federal do Rio de Janeiro. Orientadora 
ouvir, no sentido do diálogo.

Desse modo acredito que estamos falando de vida, quando paramos para refletir sobre as formas diversificadas do cuidar e ensinar em Enfermagem, pois a enfermeira tem em suas mãos algo precioso que deve ser desenvolvido em todos os momentos: o cuidado com outro. Cuidado este que envolve todo um aparato de informações que devem fundamentar o ensino e que precisam ser difundidos e articulados como um conhecimento que não termina em sala de aula, mas que possa ser considerado como o ponto de partida para uma reflexão que conduza à compreensão da prática, pois o conhecimento não é algo acabado, mas uma construção que se faz e refaz de forma dinâmica.

Através da busca contínua de conhecimentos podemos apreender, analisar e compreender o nosso cotidiano e as implicações do que fazemos de forma mais contextualizada.

Assim emerge o pesquisar, que integrado ao cuidar, proporciona uma visão mais crítica do nosso cotidiano, ou seja, de como cuidamos e ensinamos na Enfermagem. Logo este cotidiano deve envolver leituras, questionamentos e os conhecimentos sobre essa realidade do processo cuidar e ensinar vivido pelo estudante (PEREIRA \& GALPERIM, 1995).

Desse modo, este artigo apresenta uma reflexão sobre o cuidar e o ensinar na Enfermagem, visando contribuir para o novo vivenciado no Curso de Graduação pelos estudantes e de suas descobertas no início da prática profissional.

\section{APREENSÃO E O MEDO - O "NOVO" JUNTO AO INEVITÁVEL: A EXPERIÊNCIA}

Quando vivemos momentos na nossa formação profissional considerados como algo "novo", temos a impressão de que podemos errar naquilo que realizamos, o que em alguns instantes, é natural, faz parte do nosso cotidiano. Porém, ao mesmo tempo sem percebermos, estamos tendo experiências boas ou ruins que nos enriquecem, a cada momento.

No caso da Enfermagem, o estudante vive o encontro ao entrar em contato com as diversas faces do cuidar durante sua aprendizagem. Nesse encontro o novo se insere porque transforma essa fase de aquisição de conhecimentos em momentos de apreensão e medo. Só que esses momentos não estão relacionados diretamente à fuga, mas ao "novo". Algo "novo" que toma a nossa mente e transforma este momento de aprendizagem em algo inevitável e essencial para o futuro profissional Enfermeiro que é a experiência.

$\mathrm{O}$ estudante ao se conscientizar da importância do que foi apreendido pela experiência anterior tem a oportunidade de trabalhar com toda a equipe de enfermagem e com os clientes de maneira mais integrada e reflexiva, pois compreende com maior nitidez as nuances desse cuidar e ensinar dentro do campo da Enfermagem.

É importante pontuar o despertar da sensibilidade deste estudante, considerando que a sensibilidade nos torna, naturalmente, capaz de tocar e de sentir este cuidar, e porque não, também o ensinar. Afirmo isto porque como docente estas duas palavras são tão familiares que tornam a minha atuação na Enfermagem algo muito singular e sensível. Tão peculiar que possibilita a visão clara de que o cliente depende dos cuidados e da atenção direta dos profissionais de enfermagem, que buscam a manutenção da vida.

Cuidar na Enfermagem envolve a interação de enfermeiro com o cliente, o que exige o autoconhecimento e um conhecimento que abrange a sensibilidade no tocar, no olhar, no saber sentir e captar as emoções de quem estamos cuidando para cuidar (CALDAS, 1997).

Para cuidar do outro, o nosso corpo se investe de uma ...sabedoria zelosa onde a plenitude da vida é o grande alvo. Essa sabedoria se aplica na sensibilidade ...por peculiaridades que se encaixam na perspectiva do cuidar (GOTARDO, 1996).

É neste contexto que afirmo que o processo ensinar-cuidar envolve a sensibilidade de reconhecer a si mesmo (que cuida) e o outro (que recebe o cuidado) numa relação de troca constante, ou seja, pessoas em sintonia numa compreensão do ser humano como um todo, pois ... a sensibilidade é um bem precioso que deve ser preservado e desenvolvido pelo resto da vida (MIRANDA, 1996).

É com essa sensibilidade a flor da pele que o estudante de enfermagem associa os mais variados tipos de sentimentos, desde um simples toque, até nas atitudes e comportamentos que visam o bem estar do cliente. Durante suas experiências, o estudante cria e renova maneiras de encarar as dificuldades como algo positivo que precisa ser incentivado e compartilhado para descobertas de novos caminhos nunca antes percorridos ou explorados.

Ao descrever como os estudantes reagem às experiências durante o Curso de Graduação ESPÍRITO SANTO (1997), diz que:

...é no silêncio que as reações vão sendo acumuladas, as quais em algum momento, jorram como um rio represado que teve, bruscamente, suas águas lançadas no mar, ou ficam retidas como águas represadas. Mas o contido passa a ser contado quando se cria uma oportunidade para isso. 
A autora ressalta a importância de um espaço de reflexão no ensino no qual o estudante possa expressar seus sentimentos e dúvidas com liberdade em um ambiente de afetividade e troca mútua de experiências entre quem está aprendendo e ensinando a cuidar.

Até porque como diz PEREIRA (1995):

$O$ ensino deve buscar relacionar o conhecimento teórico às experiências vivenciadas pelo exercício da reflexão, entendimento, descoberta e imaginação, os quais são enriquecidas pelos trabalhos literários, culminando no desenvolvimento e entrelaçamento do pensar, conhecer e escrever num esforço para entender o vivido na escola e nos encontros com os pacientes.

\section{UM BATE-PAPO}

Bom, mas aonde chegamos?

Ao adquirirmos a experiência, obtemos conquistas que se expressam em atitudes seguras demonstradas através de ações que se inserem nos conhecimentos apreendidos durante o processo de aprendizagem que é contínuo, dinâmico e repleto de possibilidades.

HAGUETTE (1992) ao falar sobre as ações de cuidar/ensinar afirma que a sociedade consiste de pessoas que interagem e desenvolvem atividades específicas que as colocam em diferentes situações. É através desse processo que essas estruturas e organizações se estabelecem, isto é, a vida do grupo pressupõe, necessariamente uma interação entre seus membros, já que a sociedade consiste de indivíduos que interagem entre si e cuja as atividades ocorrem, predominantemente, em resposta de um ao outro, ou em relação de um ao outro.

Essas ações tornam-se reflexivas quando reconhecemos o nosso compromisso constante relacionado com o ensinar e o cuidar, o qual implica num incentivo ao estudante pensar cada vez mais no seu fazer. Ao incentivarmos sua participação em outras atividades durante o curso, incluindo a realização de trabalhos científicos com base nas suas experiências, podemos contribuir tanto para ampliar seus conhecimentos quanto favorecer a melhoria da qualidade da assistência a partir da compreensão da importância da sua atuação junto aos clientes e com os demais membros da equipe de enfermagem.

Ao escrevermos sobre nossas experiências, ao mesmo tempo realizamos um processo reflexivo que pode culminar com a possibilidade de transformação. Este paradigma escrever para aprender: “...proporciona uma nova concepção sobre o processo de pensar em escrever, considerados mutuamente importantes, no qual as habilidades constituintes do ato de escrever se aprimoram no desenvolvimento da reflexão, na busca de como expressar por escrito o que é pensado e, assim, exteriorizar e comunicar o que está no intimo, permitindo-nos desenvolver como se dá esse processo (PEREIRA, 1995).

É através das ações da prática profissional que realizo uma identificação das experiências do estudante durante sua graduação que são diversificadas e dinâmicas gerando momentos de interesse e participação, na qual a Enfermagem assume um papel de suma importância na manutenção e promoção da saúde e, por ser uma profissão que possui singularidades nos seus conhecimentos, põe em prática o seu pensar através das ações do cuidar e ensinar.

Portanto, volto a enfatizar o quanto é fundamental o incentivo ao estudante para o desenvolvimento do seu pensar crítico, para que o significado do cuidado atribuído pelo mesmo e o ensinar se tornem eficazes fundamentando e esclarecendo a prática de Enfermagem, através da descoberta e identificação de caminhos.

\section{IDENTIFICANDO CAMINHOS}

Entrar no campo da identificação é encontrar caminhos que representam uma área de interesse e de estudos. Identificar aqui representa um questionamento de nossas ações, do fazer e do pensar, que vai ao encontro da pesquisa e de descobertas de novos caminhos a serem percorridos. Penso que ao refletirmos sobre estas questões teóricas e práticas na Enfermagem talvez ocorra uma contribuição para a construção de conhecimentos contínuos e diversificados.

Sobre este aspecto PEREIRA (1995) afirma que os trabalhos literários favorecem na Enfermagem o entendimento das situações vivenciadas no cotidiano, ou seja, ... a história compartilhada por alguém permite ao outro participar da experiência através de pequenas doses de envolvimento pessoal, familiarizando-o com sentimentos situados fora de sua própria experiência pessoal.

Incentivar no estudante sua capacidade de aplicar novas descobertas não só facilita a compreensão de si mesmos, como também permite a compreensão do "outro" que depende de cuidados, tornando progressivo o caminhar na Enfermagem. Para isso, torna-se imprescindível o impulso à criatividade e ao conhecimento crítico do estudante em seu potencial 
individual e coletivo como busca incansável para transformação e desenvolvimento próprio.

Isso porque como afirma GOTARDO (1996) há a necessidade de estudos na nossa profissão que cuida do corpo a fim de alcançarmos um olhar crítico sobre a prática que se desenvolve nos nossos campos de trabalho, visando reconhece-lo como algo sensível.

Assim o estudante de enfermagem ao apreender e reconhecer, durante a sua formação, a importância da sua atuação e do seu compromisso com a profissão poderá sentir-se impulsionado a trilhar o caminho para futuras descobertas.

\section{DESCOBRINDO E REVELANDO CAMINHOS FUTUROS}

Realizar uma abordagem sobre estas questões remete a momentos de reflexão sobre como os conhecimentos são assimilados durante a vida acadêmica e profissional. Isto significa procurar novos caminhos dentro do campo da Enfermagem que tem como objetivos o cuidado e o ensino, e cujo cotidiano insere o zelo constante pela vida humana.

Compreender nossas ações pode nos levar a perceber que a Enfermagem não é somente um conjunto de técnicas, mas um processo criativo que envolve sensibilidade. O seu cuidar e ensinar vão para além das fundamentações teóricas, exigindo momentos que, somente o contato com o novo pode permitir, que é a oportunidade de troca entre pessoas: de quem cuida e de quem recebe o cuidado, assim como de quem ensina e de quem aprende a cuidar.

$\mathrm{Na}$ medida em que as idéias e os sentimentos vão sendo desvendados, o conhecimento vai adquirindo corpo e a identificação do seu pensar vai se definindo. É necessário "chamar" a participação do estudante continuamente, pois compreender a Enfermagem como ciência, no meu ver a arte da vida e porque não a ciência da vida, mobiliza-nos para o crescimento da profissão através dos estudantes, proporcionando momentos criativos que sempre se renova no cuidar e no ensinar em Enfermagem.

\section{REFLECTING ON NURSING CARE AND TEACHING}

This is a reflection on nursing care and teaching which is based on academic and professional experiences in the fields of research, teaching and community extension services. It aims at contributing to discussions on the importance of nursing students in the process of giving care and teaching as well as of their participation in scientific work, which allows the development of a more critical view on nursing teaching and practice.

KEY WORDS: nursing, reflection, teaching, care

\section{REFLEXIONANDO SOBRE EL CUIDAR Y EL ENSEÑAR EN ENFERMERÍA}

Se trata de una reflexión sobre el cuidar y enseñar en Enfermería con base en experiencias académicas y profesionales en las áreas de investigación, docencia y extensión. Tiene como objetivo contribuir para las discusiones sobre la importancia del estudiante de enfermería en el proceso de cuidar y enseñar y su participación efectiva en trabajos científicos, los cuales pueden posibilitar el desarrollo de una conciencia más critica sobre la realidad de la enseñanza y de la práctica de enfermería.

TÉRMINOS CLAVES: enfermería, reflexión, enseñanza, cuidado

\section{REFERÊNCIAS BIBLIOGRÁFICAS}

01. CALDAS, L.M.R. Um dia na UTI Pediátrica: uma análise crítica. Revista Alternativa de Enfermagem, Rio de Janeiro, v. 2, n. 5, p. 2226, 1997.

02. ESPÍRITO SANTO, F.H.do. As interações entre professoras e estudantes na trama da construção da identidade profissional da enfermeira. Rio de Janeiro, 1997. 197p. Dissertação (Mestrado) - Escola de Enfermagem Anna Nery, Universidade Federal do Rio de Janeiro.
03. GOTARDO, G.I.B. A Enfermagem arte: uma abordagem sob a ótica de Nietzsche. Revista de Enfermagem UERJ, Rio de Janeiro, v. 2, p. 131136, 1996. $\mathrm{n}^{\circ}$ extra.

04. HAGUETTE, T.M.F. Metodologias qualitativas na sociologia. 3. ed. Petrópolis: Vozes, 1992.p. 217.

05. MIRANDA, C.F.de. Atendendo o paciente Perguntas e respostas para o profissional de saúde. Belo Horizonte: Crescer, 1996. p. 257. 
06. NUNES, D.M. Vivenciando o cuidado: revelações da prática de ensino. In: MEYER, D.E.; WALDOW, V.R.; LOPES, M.J.M. (Organizadores). Marcas da adversidade: saberes e fazeres da Enfermagem contemporânea. Porto Alegre: Artes Médicas, 1998. p. 183-193.

07. PEREIRA, R.C.J. Refletindo e escrevendo sobre as experiências vivenciadas no contexto da escola e do cuidado. In: WALDOW, V.R. et al. Maneiras de cuidar/maneiras de ensinar: a Enfermagem entre a escola e a prática profissional. Porto Alegre: Artes Médicas, 1995. p. 135-149.
08. PEREIRA, R.C.J.; GALPERIM, M.R.D. Cuidando ensinando - pesquisando. In: WALDOW, V.R. et al. Maneiras de cuidar/maneiras de ensinar: a Enfermagem entre a escola e a prática profissional. Porto Alegre: Artes Médicas, 1995. p. 189-203.

09. PESSOA, C.K.L. Revelando a diferença. Revista de Enfermagem UERJ, Rio de Janeiro, v. 2, p. 6070, 1996. $\mathrm{n}^{\circ}$ extra.

10. WALDOW, V.R. Cuidar como marco de referência para o ensino da Enfermagem. In: CONGRESSO BRASILEIRO DE ENFERMAGEM, 50. Anais. Salvador, 1998. p. 197-204. 